\title{
Continuous intrathecal glyceryl trinitrate prevents delayed cerebral vasospasm in the single-SAH rabbit model in vivo
}

\author{
Ali Reza Fathi • Serge Marbacher • Thilo Graupner • \\ Felix Wehrli • Stephan M. Jakob • Gerhard Schroth • \\ Javier Fandino
}

Received: 7 December 2010 /Accepted: 6 May 2011 /Published online: 14 June 2011

(C) Springer-Verlag 2011

\begin{abstract}
Background Delayed cerebral vasospasm after aneurysmal subarachnoid hemorrhage (SAH) is a major cause of high morbidity and mortality. The reduced availability of nitric oxide (NO) in blood and cerebrospinal fluid (CSF) is well established as a key mechanism of vasospasm. Systemic administration of glyceryl trinitrate (GTN), an NO donor also known as nitroglycerin, has failed to be established in clinical settings to prevent vasospasm because of its adverse effects, particularly hypotension. The purpose of this study was to analyze the effect of intrathecally administered GTN on vasospasm after experimental SAH in the rabbit basilar artery.

Methods A single-hemorrhage model of SAH in rabbits was used to induce vasospasm. GTN $(0.5 \mathrm{mg} / \mathrm{ml})$ or saline was infused via a subcutaneous implanted osmotic pump
\end{abstract}

A. R. Fathi $\cdot$ S. Marbacher $\cdot$ T. Graupner $\cdot$ F. Wehrli $\cdot$

S. M. Jakob $\cdot$ J. Fandino

Cerebrovascular Research Group, Department of Intensive Care

Medicine, University of Berne,

Berne, Switzerland

A. R. Fathi $(\triangle) \cdot$ S. Marbacher $\cdot$ J. Fandino

Department of Neurosurgery, Kantonsspital Aarau,

Tellstrasse,

5001, Aarau, Switzerland

e-mail: ar.fathi@gmx.net

G. Schroth

Institute of Diagnostic and Interventional Neuroradiology,

University Hospital Inselspital Bern,

Bern, Switzerland

T. Graupner $\cdot$ F. Wehrli

Department of Neurosurgery, University Hospital Inselspital Bern,

Bern, Switzerland with continuous drug release into the cerebellomedullary cistern over 5 days. The degree of vasospasm in the basilar artery was recorded with angiography on day 5 after SAH and was compared to baseline angiography on day 0 .

Findings Significant reduction of basilar artery diameter was observed in the SAH group with saline infusion compared to sham-operated animals. Intrathecally administered GTN had no effect on the vessel diameter in shamoperated animals, whereas it significantly prevented vasospasm in the SAH group. Intrathecal GTN infusion did not affect arterial blood pressure.

Conclusions Prophylactic, continuous intrathecal administration of GTN prevents vasospasm of the basilar artery in the rabbit SAH model. No toxic effects could be demonstrated in this study. The clinical safety and feasibility of this strategy need to be further investigated.

Keywords Subarachnoid hemorrhage - Cerebral vasospasm · Delayed ischemic neurological deficits . Nitroglycerin $\cdot$ Nitric oxide donors

\section{Introduction}

Aneurysmal subarachnoid hemorrhage (aSAH) occurs in $\sim 15 / 100,000$ persons each year. Delayed ischemic neurological deficit (DIND) develops within 14 days after aSAH and remains the major cause of unfavorable outcome in 25 $30 \%$ of these patients $[8,9]$. The underlying causes of DIND are multifactorial. Nevertheless, arterial narrowing in the time course of DIND, also known as delayed cerebral vasospasm, is a major cause of territorial and/or lacunar brain infarctions [7].

Vasospasm itself underlies a number of different pathophysiological factors. A key factor is the reduced intraar- 
terial [16] and cerebrospinal fluid (CSF) [20, 35] concentrations of nitric oxide (NO) as an endothelial-derived relaxing factor (EDRF) after SAH. The pathophysiological mechanisms are mainly the dysfunction of the NOproducing enzyme nitric oxide synthase (NOS) and scavenging of $\mathrm{NO}$ due to the presence of deoxyhemoglobin and its high affinity for NO [6]. Based on these facts, classic NO donors [sodium nitroprusside and glyceryl trinitrate $(\mathrm{GTN})$ ] have been administered in several experimental settings since the early 1970s [21] in order to enhance NO concentrations and dilate spastic vessels.

Sodium nitroprusside is the most frequently used of these substances, and has been administered intrathecally in several human studies in order to bypass the side effects of systemic administration, such as hemodynamic hypotension and development of tolerance [24, 31]. Despite positive effects on vessel diameter, its routine clinical application has been limited by side effects, such as nausea and vomiting, cardiac arrhythmia, and intracranial hypertension. GTN has been shown to dilate cerebral vessels after experimental SAH and in the clinical setting by intravenous, intraarterial or transdermal administration. In three clinical studies, side effects similar to those seen with sodium nitroprusside developed after systemic administration of the drug (intravenous and transdermal) and therefore limited its use for treatment of vasospasm [13, 26, 29]. Intrathecal administration of GTN has not been tested in clinical studies as of yet.

In a previous study we used intrathecal GTN infusion as a control to the nimodipine infusion group [14]. Despite promising results, this study has been criticized because of remarkable vasospasm in the control group and lack of sham-operated control. More recently, Pluta et al. published a study in primates questioning the effect of intrathecally administered drugs [19]. Consequently, the present study was specifically designed to elucidate the effects of continuous intrathecal GTN on prevention of SAHinduced cerebral vasospasm in an optimized study protocol compared to a sham-operated control.

\section{Methods}

The study was performed in accordance with the National Institutes of Health guidelines for the care and use of experimental animals, and with the approval of the Animal Care Committee of the Canton of Bern, Switzerland (approval no. 63/03).

Study design

Forty-six adult male New Zealand White rabbits weighing $3-5 \mathrm{~kg}$ were randomly assigned to four experimental groups (6 animals excluded): group 1: sham operation with saline infusion $(\mathrm{n}=10)$; group 2: sham operation with continuous GTN infusion $(\mathrm{n}=10)$; group 3 : SAH with saline infusion $(\mathrm{n}=10)$; group 4: SAH with continuous GTN infusion $(n=10)$. All surgical procedures were performed under sterile conditions.

Anesthesia, monitoring, and euthanasia

Induction of general anesthesia was performed by intramuscular administration of ketamine $(30 \mathrm{mg} / \mathrm{kg})$ (Ketalar ${ }^{\circledR} 50 \mathrm{mg} / \mathrm{ml}$, Pfizer AG, Zurich, Switzerland) and xylazine $(6 \mathrm{mg} / \mathrm{kg})$ (Xylapan ${ }^{\circledR} 20 \mathrm{mg} / \mathrm{mL}$, Vétoquinol AG, Bern, Switzerland). During surgery, pain evaluation was performed periodically by toe-pinch. Postoperative pain relief was managed by subcutaneous administration of buprenorphine $\left(0.1-0.2 \mathrm{mg} / \mathrm{kg}\right.$; Temgesic ${ }^{\circledR}$ $0.3 \mathrm{mg} / \mathrm{ml}$, Essex Chemie AG, Lucerne, Switzerland) for up to $36 \mathrm{~h}$ after SAH. The animals were killed on day 5 post-SAH induction by intraarterial bolus injection of sodium thiopental $(40 \mathrm{mg} / \mathrm{kg})$ (Pentothal ${ }^{\circledR}$, Ospedalia AG, Hünenberg, Switzerland), the same anesthetic used for angiography.

Heart rate and blood pressure were monitored throughout the digital subtraction angiography (DSA) on day 0 and day 5 after experimental SAH. Intravascular pressures and heart rate were measured with a Camino $^{\circledR}$ Multi-Parameter Monitor (Integra ${ }^{\mathrm{TM}}$, Plainsboro, NJ). On the same days, arterial blood gas status was analyzed from collected arterial blood samples in order to monitor oxygenation parameters (ABL 725, Radiometer, Copenhagen, Denmark). The animals underwent daily clinical observation.

\section{Angiography}

After induction of general anesthesia by intramuscular administration of ketamine $(30 \mathrm{mg} / \mathrm{kg})$ and xylazine $(6 \mathrm{mg} / \mathrm{kg})$, DSA was performed on day 0 and day 5 , as reported previously.[15]. In brief, the rabbit's left (day 0) or right (day 5) subclavian artery was microsurgically exposed and cannulated using a 5.5-French pediatric three-lumen central venous catheter (Arrow Int. Inc., Reading, PA). Subsequently, images of the vertebro-basilar system were obtained by rapid sequential DSA using intraarterial bolus injections of non-ionic iopamidol $\left(0.6 \mathrm{ml} / \mathrm{kg}\right.$; Iopamiro ${ }^{\circledR}$ $300 \mathrm{mg} / \mathrm{ml}$, Bracco, Milan, Italy) as contrast agent. The average diameter of the basilar artery (BA) was digitally calculated in $\mu \mathrm{m}$ using the automatic measurement tool of the ImagePro Discovery ${ }^{\circledR}$ analysis software (Media Cybernetics, Bethesda, MD). Measurements were performed by three blinded investigators, and mean values were used for statistical analysis. 


\section{Cerebral vasospasm model}

Following baseline DSA on day 0, the atlanto-occipital membrane was microscopically exposed, and a 25 -gauge needle was inserted into the cerebromedullary cistern. After relief of $1.0 \mathrm{~mL}$ of CSF, an equal amount of nonheparinized autologous arterial blood (saline in sham group) was injected into the cistern under microscopic view [3]. The rabbits were kept positioned at a $65^{\circ}$ angle, head-down, for $10 \mathrm{~min}$ in order to allow blood dissemination throughout the subarachnoidal space.

Implantation of miniosmotic pump

A miniosmotic pump $(0.5 \mu \mathrm{l} / \mathrm{h}$, model $1007 \mathrm{D}$, Alzet Osmotic Pumps, Durect, Cupertino, CA) containing either $0.5 \mathrm{mg} / \mathrm{ml}$ of GTN solution (pH 7.35; Perlinganit, Schwarz Pharma, Münchenstein, Switzerland) or sodium chloride $(\mathrm{NaCl})$ was implanted subcutaneously. This pump model ensures a drug release over 7 days. The dose of GTN was derived from studies with sodium nitroprusside administration in humans in which up to $8 \mathrm{mg} / 24 \mathrm{~h}$ was used for prophylaxis against vasospasm [30, 31]. Pumps, associated tubing, and drugs were protected from light at all times. A silicone catheter (STH-C040, Connectors Verbindungstechnik, Tagelswangen, Switzerland) was connected to the pump and inserted under microscopic view at least $1 \mathrm{~mm}$ through the atlanto-occipital membrane into the subarachnoid space. The tube insertion site was sealed by a muscle patch and fixed by several stitches. The midline spinal muscle incision was closed in two layers. Finally, the wounds were superficially irrigated with neomycin sulfate (Research Organics, Cleveland, $\mathrm{OH})$ for infection prophylaxis.

Statistical methods

Values were expressed as a mean in each group \pm SEM ( $n=$ number of animals). Statistical significance between two means and multiple means was determined by parametric one-way ANOVA and Bonferroni's multiple comparisons post-testing, respectively. Statistical significance was con- sidered if the $P$ value was less than $0.05(p<0.05)$ in the context of $95 \%$ confidence intervals of the differences examined (95\% CI of difference).

\section{Results}

Physiological data

Mean arterial blood pressure (mean $73 \pm 12.64 \mathrm{mmHg}$ ) and heart rate (mean $165.5 \pm 5.9$ ) were not significantly different among the study groups $(\mathrm{p}>0.05)$. Blood gas analysis showed no significant difference for $\mathrm{pCO}_{2}$ (mean $43.79 \pm$ $5.50 \mathrm{mmHg}, \mathrm{p}>0.05$ ), $\mathrm{pO}_{2}$ (mean $77.8 \pm 10.4 \mathrm{mmHg}, \mathrm{p}>$ 0.05 ), or $\mathrm{pH}$ (mean $7.37 \pm 0.1, \mathrm{p}>0.05$ ) (Table 1).

Morbidity, mortality, and neurological status

Five rabbits had to be euthanized before completion of the studies because of poor clinical conditions and were excluded from analysis. Three of them had permanent paralysis of the lower extremities after SAH induction, while two other animals had loss of appetite and deteriorated in general condition. Clinical daily follow-up of the remaining animals was uneventful up to day 5. Gross pathological evaluation revealed no signs of infection. All of the implanted pump devices were precisely placed 1$2 \mathrm{~mm}$ beneath the atlanto-occipital membrane.

Angiographic measurements

A total of 80 angiograms of the basilar artery were analyzed. There were no significant differences in the intra- and interobserver analyses $(p>0.05)$. Baseline vessel diameter on day 0 did not significantly differ among the six experimental groups. Basilar artery diameter changes in sham-operated animals were not significantly different between saline $(4.57 \pm 3.6 \%)$ and GTN $(8.8 \pm 5.1 \%)$ groups $(\mathrm{p}>0.05)$. In the SAH group with saline infusion, basilar artery diameter was significantly reduced $(16.2 \pm 2.8 \%)$ on day 5 compared to baseline values $(p<0.05)$. The BA

Table 1 Physiological data of the animals during final angiogram

\begin{tabular}{|c|c|c|c|c|}
\hline & $\mathrm{Sham} / \mathrm{NaCl}$ & Sham/GTN & $\mathrm{SAH} / \mathrm{NaCl}$ & $\mathrm{SAH} / \mathrm{GTN}$ \\
\hline MABP $(\mathrm{mmHg})$ & $72.8 \pm 4.3$ & $73.5 \pm 2.1$ & $74.2 \pm 2.4$ & $70.9 \pm 2.6$ \\
\hline Heart Rate & $159 \pm 6$ & $163 \pm 4.8$ & $168 \pm 5.4$ & $172 \pm 7.5$ \\
\hline $\mathrm{pO}_{2}(\mathrm{mmHg})$ & $79.4 \pm 14.1$ & $80.5 \pm 14.4$ & $76.1 \pm 7.1$ & $75.3 \pm 5.9$ \\
\hline $\mathrm{pCO}_{2}(\mathrm{mmHg})$ & $44.6 \pm 1.1$ & $43.8 \pm 2.3$ & $41.5 \pm 3.5$ & $44.7 \pm 2.2$ \\
\hline $\mathrm{pH}$ & $7.4 \pm 0.01$ & $7.36 \pm 0.02$ & $7.37 \pm 0.02$ & $7.36 \pm 0.02$ \\
\hline
\end{tabular}

There is no significant difference for each parameter between the groups. NaCl: sodium chloride, GTN: glyceryl trinitrate, SAH: subarachnoid hemorrhage, MABP: mean arterial blood pressure. Values are mean \pm standard error of mean 


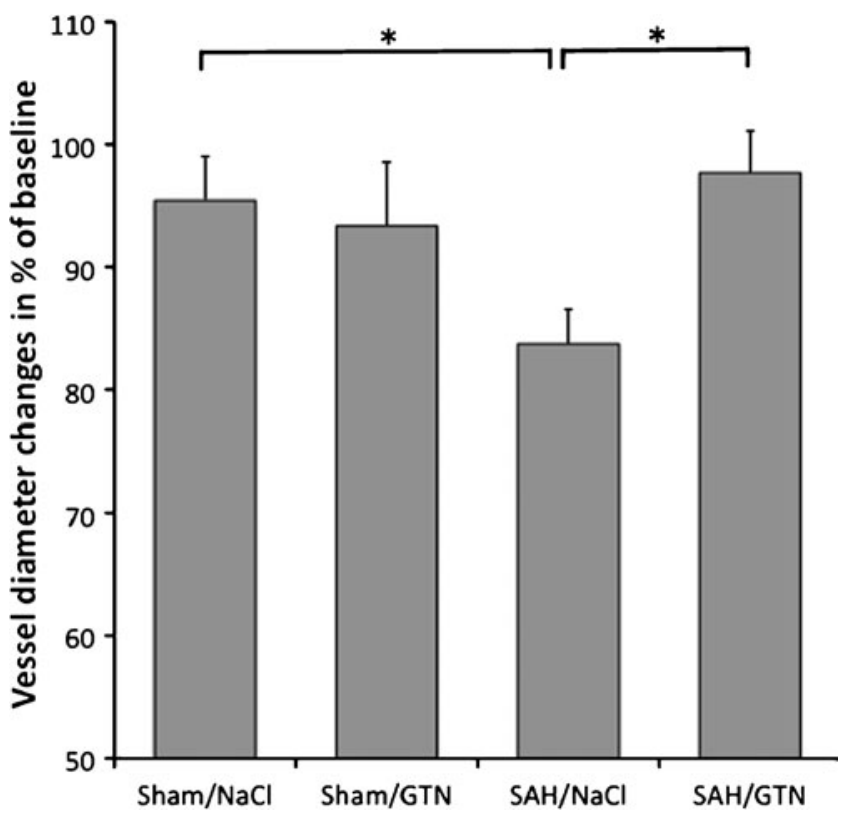

Fig. 1 Relative changes of basilar artery diameter compared to baseline angiograms. Glyceryl trinitrate (GTN) has no significant effect on the basilar artery in sham-operated animals. Subarachnoid hemorrhage $(\mathrm{SAH})$ induces significant vasospasm in the basilar artery, while GTN prevents vasospasm $(* p<0.05)$

diameter after SAH and continuous GTN showed significant prevention of the vessel constriction and was reduced by only $2.29 \pm 3.4 \%(p<0.05$; Fig. 1$)$.

\section{Discussion}

This study confirms that intrathecal continuous infusion of GTN prevents delayed cerebral vasospasm of the rabbit basilar artery after SAH.

Nitric oxide donors have been proven to be effective for reversal and prevention of vasospasm in experimental and clinical trials for almost 4 decades [1, 21]. However, routine clinical application has been limited because of systemic side effects. Intravenous and transdermal GTN have been tested in three clinical trials showing dilative effects on vessel diameter (Table 2) [13, 26, 29]. However, further clinical evaluation was abandoned because of systemic side effects. Although several animal studies have shown a beneficial effect of GTN (Table 3), the effect of intrathecal GTN administration with the intention of bypassing these side effects has not been conclusively investigated. In a previous study with intrathecal nimodipine and GTN, we have shown the feasibility of intrathecal administration of GTN [14]. The present study confirms that intrathecal administration of GTN is safe and prevents vasospasm at lower dosage over 5 days of infusion in a rabbit model.

The clinical status and the arterial blood pressure at day 5 did not indicate a drop in blood pressure compared to day 0 . Since $\mathrm{pH}$ and $\mathrm{pO}_{2}$ can alter $\mathrm{pCO}_{2}$ and thus influence cerebral autoregulation and vessel diameter [4], we excluded the effect of these parameters by maintaining comparable values in all study groups. However, we did not measure the concentration of the NO metabolome in CSF and in blood for correlation studies with clinical data.

Another limitation of the systemic application of GTN as prescribed for long-term use in angina pectoris treatment is the development of drug tolerance [10]. Since the vasodilatory effect is present after 5 days of continuous infusion, we conclude that there is no drug tolerance in this short period of treatment. Considering that peak vasospasm after SAH occurs between days 3 and 14, we do not expect tolerance to develop during short-term treatment in SAH patients receiving GTN.

Pluta et al. investigated the extent of intrathecal drug distribution around the middle cerebral artery in the primate model of SAH and expressed concern about sufficient drug penetration through the blood clot to the artery [19]. However, the present study, like others with sodium nitroprusside, has demonstrated that this limitation does not apply to NO donors since the vasoactive effect remains unaffected by the presence of the blood clot. The main

Table 2 Clinical studies with nitroglycerin

\begin{tabular}{|c|c|c|c|c|c|c|}
\hline Author & Year & Journal & $\begin{array}{l}\text { Administration } \\
\text { route }\end{array}$ & Assessment method & Results & Comments \\
\hline Tanaka & 2001 & Acta Neurochirurgica & Intravenous & Neurological outcome & $\begin{array}{c}\text { DIND } 24 \% \text { in nitroglycerin group } \\
\text { vs. } 60 \% \text { in Fasudil group alone }\end{array}$ & $\begin{array}{l}25 \text { patients in combination } \\
\text { with Fasudil }\end{array}$ \\
\hline Lesley & 2003 & $\begin{array}{l}\text { American Journal } \\
\text { of Neurorad }\end{array}$ & Transdermal & Arteriogram & $\begin{array}{l}\text { Improvement of CVS signs in all } \\
\text { patients (no outcome data) }\end{array}$ & 5 patients, technical note \\
\hline Reinert & 2004 & Neurological Research & Transdermal & TCD and CT perfusion & $\begin{array}{l}\text { TCD velocity significantly } \\
\text { decreased in nitroglycerin group }\end{array}$ & 9 patients, 8 controls \\
\hline
\end{tabular}

None of the human studies tested intrathecal administration of nitroglycerin

TCD: Transcranial Doppler 
Table 3 Experimental studies with nitroglycerin

\begin{tabular}{lllllll}
\hline Author & Year & Journal & Animal type & In vivo/ex vivo & Administration route & Assessment method \\
\hline Poletti & 1972 & Surg Forum & Dog & In vivo & Local perivascular & In vivo visualization \\
Kistler & 1979 & Stroke & Dog & In vivo & Intravenous & Arteriogram \\
Shimizu & 1980 & Stroke & Dog & Ex vivo & Local perivascular & Ex vivo analysis \\
Frazee & 1981 & J Neurosurg & Primate & In vivo & Intravenous & Arteriogram \\
VonEssen & 1981 & Stroke & Dog & In vivo & Intravenous & CBF and ICP \\
Kistler & 1982 & Arch Neurolo & Primate & In vivo & Intravenous and intraarterial & Arteriogram \\
Liszczak & 1983 & J Neurosurg & Dog & In vivo & Intravenous & Arteriogram \\
Kanamaru & 1989 & J Neurosurg & Primate & In vivo & Local perivascular & Ex vivo analysis \\
Nakao & 1996 & Stroke & Primate & In vivo & Intravenous & Arteriogram \\
Thomas & 1997 & Neurosurgery & Rabbit & In vivo & Local perivascular & In vivo visualization \\
Ito & 2000 & J Cardiovasc Pharmacol & Rabbit & In vivo & Transdermal & Arteriogram \\
Tanaka & 2001 & Neurol Med Chir (Tokyo) & Dog & Ex vivo & Local perivascular & Ex vivo analysis \\
Marbacher & 2008 & Intensive Care Medicine & Rabbit & In vivo & Intrathecal & Arteriogram \\
\hline
\end{tabular}

TCD: Transcranial Doppler, CBF: Cerebral blood flow, ICP: Intracranial pressure

reason for this might be that the viscosity of Evans blue (in Pluta's study) [19] is not comparable to the viscosity of nitric oxide donors, and moreover, once NO is released from GTN, it has very high tissue permeability and diffuses freely across membranes.

Another concern with intrathecal administration of drugs is catheter infections resulting in meningitis and ventriculitis. Infection risk might be reduced by implanting antibiotic-impregnated catheters [28]. Moreover, the intrathecal route might become more accessible since studies with intrathecal rTPA, cisternal washing, and lumbar CSF drainage may be more applicable in combination with NO donors and similar drugs that are more feasibly administered this way [11].
Intrathecal sodium nitroprusside, a different class of $\mathrm{NO}$ donor, is the only NO donor that has been tested intrathecally in clinical studies after $\mathrm{SAH}$, and has also been proven to dilate constricted vessels (Table 4) [1, 12, 17, 18, 23, 24, 30, 31, 33]. However, systemic side effects, especially cyanide poisoning [25], have limited further use of this drug. Since GTN has different mechanisms of NO release than sodium nitroprusside, distinct patterns of adverse effects are expected. However, this has yet to been confirmed and evaluated in clinical studies.

Our study confirms the important role of NO in the pathophysiology of vasospasm, as reported with other classes of NO donors in experimental settings. Among them, NONOates represent a distinct class of NO donors

Table 4 Clinical studies with Sodium nitroprusside as an NO donor and intrathecal application

\begin{tabular}{|c|c|c|c|c|c|}
\hline Author & Year & Journal & Results & Assessment method & Comments \\
\hline Thomas & 1999 & Neurosurgery & Reversal, all 3 patients with good outcome & Arteriogram and TCD & 3 patients \\
\hline Thomas & 1999 & Stroke & Reversal in $6 / 15$ patients & Arteriogram and TCD & 15 patients \\
\hline Vajkoczy & 2000 & Stroke & Reversal of CVS & $\mathrm{CPP}$, brain $\mathrm{O}_{2}$ saturation & Case report \\
\hline Raabe & 2002 & JNNP & Reversal of CVS & Brain $\mathrm{O}_{2}$ saturation & Case report \\
\hline Raabe & 2002 & Neurosurgery & $\begin{array}{l}1 \text { patient with angiographic reversal, no } \\
\text { difference in outcome between treated } \\
\text { and untreated patients }\end{array}$ & $\begin{array}{l}\text { Arteriogram and brain } \\
\mathrm{O}_{2} \text { saturation }\end{array}$ & 13 patients \\
\hline Kumar & 2003 & Neurol India & Reversal, good outcome in $6 / 10$ & Arteriogram and TCD & 10 patients \\
\hline Pathak & 2003 & Br J Neurosurg & $\begin{array}{l}\text { Prevention and reversal, good outcome } \\
\text { in } 5 / 8 \text { patients }\end{array}$ & TCD & 8 patients \\
\hline Pachl & 2005 & Acta Neurochirurgica & Prevention in $13 / 17$ & TCD, GCS & $\begin{array}{l}16 \text { patients, inhomogeneous } \\
\text { study design }\end{array}$ \\
\hline Agrawal & 2009 & Minim Invas Neurosurg & Reversal, good outcome in $7 / 10$ & TCD & 10 patients \\
\hline
\end{tabular}

TCD: Transcranial Doppler, CPP: Cerebral perfusion pressure, GCS: Glasgow Coma Scale 
that have been tested intrathecally in animal studies using polymer pellets $[2,22,32,34]$. Other than one study in primates [2], all other studies with NONOates have shown significant vessel dilation. One drawback with NONOates is that they have been shown to open the blood-brain barrier at higher doses und thus provoke brain infarction and toxicity [5]. Other classes of NO donors that have been tested in experimental settings are S-nitrosothiols and sodium nitrite $[20,27]$. Preliminary results are very promising, but the therapeutic value has yet to be confirmed.

Despite certain limitations of the single-hemorrhage rabbit model of SAH, it provides a reliable screening method to evaluate the therapeutic potential of various drugs. This applies particularly to the vast array of nitric oxide donors and the need to investigate doses and administration routes. This study serves as a proof of concept for development of new treatment strategies such as intrathecal delivery of $\mathrm{NO}$ donors. It is of utmost importance to consider the multifactorial course of the disease, and thus to consider the therapeutic aspects as multidirectional as well. This includes the neuroprotective effect of nimodipine, optimized clinical management, NO donors, and antiinflammatory therapeutics. In this multidirectional treatment approach one goal should be the reduction of individual drug dosages in order to minimize side effects.

Many patients are referred several days after SAH and may present with clinical and angiographic signs of vasospasm. Whether intrathecal GTN can reverse established vasospasm in this specific patient group remains unclear. Thus, addition studies are warranted to address the effect of intrathecal NO not only for prevention but also for reversal of vasospasm.

\section{Conclusion}

Intrathecal administration of the NO donor GTN attenuates vasospasm in the rabbit single-hemorrhage SAH model. Further experimental and clinical evaluation of different classes of NO donors is necessary in order to ascertain the best source and administration route of $\mathrm{NO}$ and to optimize its therapeutic potential.

\section{Conflicts of interest None.}

\section{References}

1. Agrawal A, Patir R, Kato Y, Chopra S, Sano H, Kanno T (2009) Role of intraventricular sodium nitroprusside in vasospasm secondary to aneurysmal subarachnoid haemorrhage: a 5-year prospective study with review of the literature. Minim Invasive Neurosurg 52:5-8
2. Aihara Y, Jahromi BS, Yassari R, Sayama T, Macdonald RL (2003) Effects of a nitric oxide donor on and correlation of changes in cyclic nucleotide levels with experimental vasospasm. Neurosurgery 52:661-667, discussion 666-667

3. Fandino J, Sherman JD, Zuccarello M, Rapoport RM (2003) Cocaine-induced endothelin-1-dependent spasm in rabbit basilar artery in vivo. J Cardiovasc Pharmacol 41:158-161

4. Faraci FM, Breese KR, Heistad DD (1994) Cerebral vasodilation during hypercapnia. Role of glibenclamide-sensitive potassium channels and nitric oxide. Stroke 25:1679-1683

5. Gabikian P, Clatterbuck RE, Eberhart CG, Tyler BM, Tierney TS, Tamargo RJ (2002) Prevention of experimental cerebral vasospasm by intracranial delivery of a nitric oxide donor from a controlled-release polymer: toxicity and efficacy studies in rabbits and rats. Stroke 33:2681-2686

6. Gow AJ, Stamler JS (1998) Reactions between nitric oxide and haemoglobin under physiological conditions. Nature 391:169173

7. Hansen-Schwartz J, Vajkoczy P, Macdonald RL, Pluta RM, Zhang JH (2007) Cerebral vasospasm: looking beyond vasoconstriction. Trends Pharmacol Sci 28:252-256

8. Hop JW, Rinkel GJ, Algra A, van Gijn J (1997) Case-fatality rates and functional outcome after subarachnoid hemorrhage: a systematic review. Stroke 28:660-664

9. Kassell NF, Torner JC (1984) The International Cooperative Study on Timing of Aneurysm Surgery-an update. Stroke 15:566-570

10. Klemenska E, Beresewicz A (2009) Bioactivation of organic nitrates and the mechanism of nitrate tolerance. Cardiol J 16:1119

11. Klimo P Jr, Kestle JR, MacDonald JD, Schmidt RH (2004) Marked reduction of cerebral vasospasm with lumbar drainage of cerebrospinal fluid after subarachnoid hemorrhage. J Neurosurg $100: 215-224$

12. Kumar R, Pathak A, Mathuriya SN, Khandelwal N (2003) Intraventricular sodium nitroprusside therapy: a future promise for refractory subarachnoid hemorrhage-induced vasospasm. Neurol India 51:197-202

13. Lesley WS, Lazo A, Chaloupka JC, Weigele JB (2003) Successful treatment of cerebral vasospasm by use of transdermal nitroglycerin ointment (Nitropaste). AJNR Am J Neuroradiol 24:1234-1236

14. Marbacher S, Neuschmelting V, Graupner T, Jakob SM, Fandino J (2008) Prevention of delayed cerebral vasospasm by continuous intrathecal infusion of glyceroltrinitrate and nimodipine in the rabbit model in vivo. Intensive Care Med 34:932-938

15. Neuschmelting V, Fathi AR, Hidalgo Staub ET, Marbacher S, Schroth G, Takala J, Jakob SM, Fandino J (2009) Norepinephrineinduced hypertension dilates vasospastic basilar artery after subarachnoid haemorrhage in rabbits. Acta Neurochir (Wien) 151:487-493

16. Neuschmelting V, Marbacher S, Fathi AR, Jakob SM, Fandino J (2009) Elevated level of endothelin-1 in cerebrospinal fluid and lack of nitric oxide in basilar arterial plasma associated with cerebral vasospasm after subarachnoid haemorrhage in rabbits. Acta Neurochir (Wien) 151:795-801, discussion 801-792

17. Pachl J, Haninec P, Tencer T, Mizner P, Houst'ava L, Tomas R, Waldauf $P$ (2005) The effect of subarachnoid sodium nitroprusside on the prevention of vasospasm in subarachnoid haemorrhage. Acta Neurochir Suppl 95:141-145

18. Pathak A, Mathuriya SN, Khandelwal N, Verma K (2003) Intermittent low dose intrathecal sodium nitroprusside therapy for treatment of symptomatic aneurysmal SAH-induced vasospasm. Br J Neurosurg 17:306-310

19. Pluta RM, Butman JA, Schatlo B, Johnson DL, Oldfield EH (2009) Subarachnoid hemorrhage and the distribution of drugs delivered into the cerebrospinal fluid. J Neurosurg 
20. Pluta RM, Dejam A, Grimes G, Gladwin MT, Oldfield EH (2005) Nitrite infusions to prevent delayed cerebral vasospasm in a primate model of subarachnoid hemorrhage. JAMA 293:14771484

21. Poletti CE, Wepsic JG, Sweet WH (1972) Middle cerebral arterial spasm from subarachnoid blood: spasmolysis with topical use of nitroglycerin. Surg Forum 23:449-450

22. Pradilla G, Thai QA, Legnani FG, Hsu W, Kretzer RM, Wang PP, Tamargo RJ (2004) Delayed intracranial delivery of a nitric oxide donor from a controlled-release polymer prevents experimental cerebral vasospasm in rabbits. Neurosurgery 55:1393-1399, discussion 1399-1400

23. Raabe A, Vatter H, Zimmermann M, Seifert V (2002) Reversal of tissue hypoxia by a single intraventricular dose of sodium nitroprusside in a patient with severe medically refractory cerebral vasospasm after subarachnoid haemorrhage. J Neurol Neurosurg Psychiatry 72:123-124

24. Raabe A, Zimmermann M, Setzer M, Vatter H, Berkefeld J, Seifert V (2002) Effect of intraventricular sodium nitroprusside on cerebral hemodynamics and oxygenation in poor-grade aneurysm patients with severe, medically refractory vasospasm. Neurosurgery 50:1006-1013, discussion 1013-1004

25. Ram Z, Spiegelman R, Findler G, Hadani M (1989) Delayed postoperative neurological deterioration from prolonged sodium nitroprusside administration. Case report. J Neurosurg 71:605-607

26. Reinert M, Wiest R, Barth L, Andres R, Ozdoba C, Seiler R (2004) Transdermal nitroglycerin in patients with subarachnoid hemorrhage. Neurol Res 26:435-439

27. Sehba FA, Ding WH, Chereshnev I, Bederson JB (1999) Effects of S-nitrosoglutathione on acute vasoconstriction and glutamate release after subarachnoid hemorrhage. Stroke 30:1955-1961

28. Sloffer CA, Augspurger L, Wagenbach A, Lanzino G (2005) Antimicrobial-impregnated external ventricular catheters: does the very low infection rate observed in clinical trials apply to daily clinical practice? Neurosurgery 56:1041-1044, discussion 1041-1044

29. Tanaka Y, Masuzawa T, Saito M, Yamada T, Ebihara A, Iwasa H, Mori S (2001) Combined administration of Fasudil hydrochloride and nitroglycerin for treatment of cerebral vasospasm. Acta Neurochir Suppl 77:205-207

30. Thomas JE, Rosenwasser RH (1999) Reversal of severe cerebral vasospasm in three patients after aneurysmal subarachnoid hemorrhage: initial observations regarding the use of intraventricular sodium nitroprusside in humans. Neurosurgery 44:48-57, discussion $57-48$

31. Thomas JE, Rosenwasser RH, Armonda RA, Harrop J, Mitchell W, Galaria I (1999) Safety of intrathecal sodium nitroprusside for the treatment and prevention of refractory cerebral vasospasm and ischemia in humans. Stroke 30:1409-1416

32. Tierney TS, Clatterbuck RE, Lawson C, Thai QA, Rhines LD, Tamargo RJ (2001) Prevention and reversal of experimental posthemorrhagic vasospasm by the periadventitial administration of nitric oxide from a controlled-release polymer. Neurosurgery 49:945-951, discussion 951-943

33. Vajkoczy P, Hubner U, Horn P, Bauhuf C, Thome C, Schilling L, Schmiedek P, Quintel M, Thomas JE (2000) Intrathecal sodium nitroprusside improves cerebral blood flow and oxygenation in refractory cerebral vasospasm and ischemia in humans. Stroke 31:1195-1197
34. Wolf EW, Banerjee A, Soble-Smith J, Dohan FC Jr, White RP, Robertson JT (1998) Reversal of cerebral vasospasm using an intrathecally administered nitric oxide donor. J Neurosurg 89:279-288

35. Woszczyk A, Deinsberger W, Boker DK (2003) Nitric oxide metabolites in cisternal CSF correlate with cerebral vasospasm in patients with a subarachnoid haemorrhage. Acta Neurochir (Wien) 145:257-263, discussion 263-254

\section{Comment}

In the present report, the authors have studied the effects of intrathecal administration of the NO donor glyceryl trinitrate using a singlehemorrhage model in the rabbit. GTN is shown to reduce the SAHassociated vasoconstriction of the basilar artery by approximately $10 \%$ during a 5-day infusion protocol using osmotic mini pumps. The results are statistically significant but seem to be not too impressive with respect to clinical relevance, especially in light of the drawbacks of the single-hemorrhage model in the rabbit. On the other hand, this study may serve as a proof of concept for further development of strategies that aim at local delivery of NO donors to the basal cisterns. We strongly believe that the recent, disappointing results with the systemic administration of vasoactive drugs in order to prevent cerebral vasospasm underline the necessity of promoting alternative routes of drug administration, especially directly to the affected blood vessels. This can be achieved by using continuous infusion techniques or the use of slow-release formulations. For the future, this certainly is the most promising concept for achieving an optimal vasodilatory effect at the vessels and, at the same time, avoiding systemic side effects that might counteract the beneficial effect of the drug.

Peter Vajkoczy

Berlin, Germany

This paper explores the use of nitiric oxide donors in the intrathecal space for the treatment of subarachnoid hemorrhage. The topic itself is not new. Intrathecal pumps and intrathecal polymers delivering nitric oxide agents directly to the subarachnoid space have been tested in trials over the last several years, mostly with encouraging reductions in pathological markers of vasospasm. In the vein of these past studies, the authors have demonstrated that glyceryl trinitrate, a compound previously abandoned as a systemic therapy for vasospasm, may have genuine therapeutic value as an intrathecal agent. They demonstrate that intrathecal delivery of this nitric oxide donor does not produce the same prohibitive hypotension noted in systemic administration. While they also demonstrate that basilar artery diameter reduction was less with the experimental arm, it would be interesting to know whether delayed administration of this drug would produce similar results. Few patients, after all, could have intrathecal administration of a drug immediately with their aneurismal rupture. The concept is clever and promising, and we hope to learn more from this group.

Markus J. Bookland

Christopher Loftus

Philadelphia, PA 